\title{
Myoelectrical activity of muscles stabilizing the sacroiliac joints before and after the use of elastic tapes in women suffering from Pregnancy-related Pelvic Girdle Pain
}

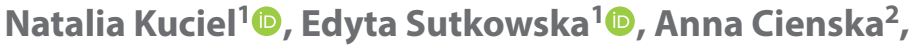 \\ Dominika Markowska ${ }^{3}$, Zdzislawa Wrzosek ${ }^{4}$ (1) \\ ${ }^{1}$ Department and Division of Medical Rehabilitation, Wroclaw Medical University, Poland \\ ${ }^{2}$ Fizis. Functional Rehabilitation, Wroclaw, Poland \\ ${ }^{3}$ Department of Physiotherapy in Internal Diseases, University School of Physical Education in Wroclaw, Poland \\ ${ }^{4}$ Department of Physiotherapy in Orthopaedic and Traumatologic Surgery, University School of Physical Education in Wroclaw, Poland
}

\begin{abstract}
Objectives: The aim of this study was the analysis of activity of selected muscles stabilizing the sacroiliac joints in pregnant women suffering from pelvic pain and changes in the pattern in response to the implementation of Kinesio Taping (elastic tape).

Material and methods: Seventeen women with Pregnancy-related Pelvic Girdle Pain and 20 pregnant women without pain in the lumbar-pelvic complex were enrolled into the study. In patients with pelvic pain, the parameters describing the action of the muscles were assessed: before the tape was applied, immediately after application, 3 days into application and 5 days after the cessation of taping. In the control group, the test was carried out one time. The activity of the muscles was measured during extension of the hip from a four-point kneeling position.

Results: The gluteus maximus muscle shows higher resting activity values than in the control group, before and after application of the tape as well as five days after the removal of the tape. Before application, the gluteus maximus activates quicker than in the control group while the ipsilateral extensor spinae had a delayed activation when compared to the control group.

Conclusions: The patterns of activation of tested muscles and their action potential values are different in the group of women with pelvic pain compared to the group without pelvic pain. The application of KT in the lumbar region appears to alter the activation of the GM muscle as well as improve activation of IES muscle during hip extension from the four-point-kneeling position.
\end{abstract}

Key words: pelvic pain; back pain; electromyography; pregnancy; motor activity

Ginekologia Polska 2020; 91, 4: 223-230

\section{INTRODUCTION}

Pregnancy-related Pelvic Girdle Pain (PPGP) is a common problem which affects the normal daily functioning of pregnant women [1]. According to the literature this problem concerns about $20 \%$ of women, however some of the evidence suggests even about $50 \%$ of women are affected [2-4] or 70-80\% [5]. Etiology of PPGP remains unclear and the main potential factors are hormonal, biomechanical, post-traumatic, or degenerative. Appearance of low back pain (LBP) before pregnancy and psychosocial factors seem to be important in the occurrence of PPGP [6]. PPGP deteriorates quality of life (QoL), activities such as bending, lifting, sleeping, prolonged walking, sitting and standing [1, 7].

Despite growing interest in this problem, objective, valid, and consistent research about the biomechanics and therapies of PPGP are still missing [8, 9]. Due to the developing fetus in pregnancy, the use of pharmacotherapy, including pain medications, is limited. For this reason, other, non-pharmacological 
methods of treatment are sought. Interest is mainly placed in physiotherapeutic methods. Kinesio Taping method (KT) was developed in 1970. by Dr. Kenzo Kase, who applied elastic tape on the skin to improve body's ability to self-regeneration [7]. Original Japanese tape, Kinesio Tex Gold, consists of cotton and acrylic copolymer and the tape's surface is interrupted by wave-shaped folds to allow skin contact with the air [10]. Kinesio Taping is a safe and non-invasive method, which forms a sort of feedback for proprioceptors, acting on both muscles in the taped area as well as tissues located beneath the tape. Tape application lifts the skin from the tissues beneath what improves blood flow under taped area [11].

Improvement of the previously mentioned motor control is only possible if the physiological mechanisms underpinning the proper cooperation of all components are understood. Thus, the evaluation of surface electromyography (sEMG) [12] seems to be the most helpful method in determining motion patterns, pinpointing any pathologies as well as the effectiveness of therapy, potentially restoring physiological muscle tension for the referenced segment of the lumbar-pelvic complex. sEMG has been used for over 40 years to characterize muscle activity pattern [12]. The electromyogram registers the sum of the actions of the motor units during the contraction of the evaluated muscle. The most often described measurements in sEMG are amplitude and activation order of the tested muscles. The amplitude indicates the extent to which a given muscle activates in the test, meanwhile the changes in the time of muscle activation can influence the motor control $[12,13]$.

\section{Objectives}

The aim of the study was the analysis of myoelectrical activity of the muscles stabilizing the sacroiliac joints (SIJ) in a group of pregnant women suffering from PPGP before and after implementation of KT, based on the analysis of amplitude and activation order of selected muscles. We hypothesize that women with PPGP have different resting and motion activity as well as changed order of activity of the tested muscles during hip extension compared to the activation pattern in healthy controls. Based on mechanism of action of the KT method we also hypothesize that physiological pattern of the muscle activity can be regained by KT.

\section{MATERIAL AND METHODS}

\section{Study design}

A total of 45 women with or without PPGP was enrolled in this non-randomised interventional study between July and December of 2013. Women who were identified by physiotherapist as suffering from PPGP were treated with KT for 5 days (Fig. 1). Before KT as applied, sEMG analysis for women with PPGP as well as for healthy participants was done to show potential differences between both groups. On the $3^{\text {rd }}$ day of tape application and 5 days after completion of KT treatment the sEMG test was applied in intervention group. No other pain management intervention was used. No other pain release intervention was used. Inclusion criteria for both groups: written permission of the patient and her primary physician to participate in the study, an uncomplicated single fetus pregnancy, 18-35 week of pregnancy, age $20-40$ at the beginning of the study. Additional criteria for IG were: confirmation of pain in the pelvic region, positive results of the three tests: Posterior Pelvic Pain Provocation (4P) [1], Long Dorsal Ligament (LDSL) [10], as well as modified Trendelenburg Test $[1,10]$ and a negative Straight Leg Raise test (SLR) [11]. The last test was used to disqualify patients with pain generated in the lumbar spine region.

Exclusion criteria included: the occurrence of other pain symptoms originating from the pelvis diagnosed earlier by the patient's primary physician, as well as acute spinal pain syndrome at the beginning of the study. Allergy to acrylic was another criteria for participants to be included in the IG.

The study was carried out in accordance with the Helsinki Declaration and was approved by the Bioethics Commission of Wroclaw Medical University (Bioethics Commission Specific Number: KB-551/2012 dated July 7, 2012) before the commencement the study.

\section{Participants \\ Intervention group (IG)}

In total, 25 women with self-reported PPGP attending classes at a birthing school were recruited and qualified for the study into the intervention group. The participants filled out a questionnaire and gave consent to participate in the study. Information about the age (years), height (m) and weight $(\mathrm{kg})$ before pregnancy, Body Mass Index (BMI) (calculated by examiner on the basis of information reported by the participants), week of pregnancy, occupation (static/dynamic kind of work) was gathered. Medical history was collected, containing information: internal diseases in pregnancy, LBP incident before pregnancy and topography of the pain during participation in the study [1]. Additionally, patients from the IG filled out a Visual Analogue Scale (VAS) for the purposes of grading the intensity of the pain. The whole group of patients underwent sEMG assessment and appropriate examinations and tests to confirm PPGP. Five women were excluded from the study due to high rate of artifacts on sEMG examination which made the test non-diagnostic. Three additional women backed out of the experiment without providing a reason. Finally, seventeen women with PPGP were included and analyzed in the study.

\section{Control group (CG)}

Twenty women attending classes at a birthing school who did not report PPGP were recruited and qualified for the 
45 pregnant women from Birthing School recruited

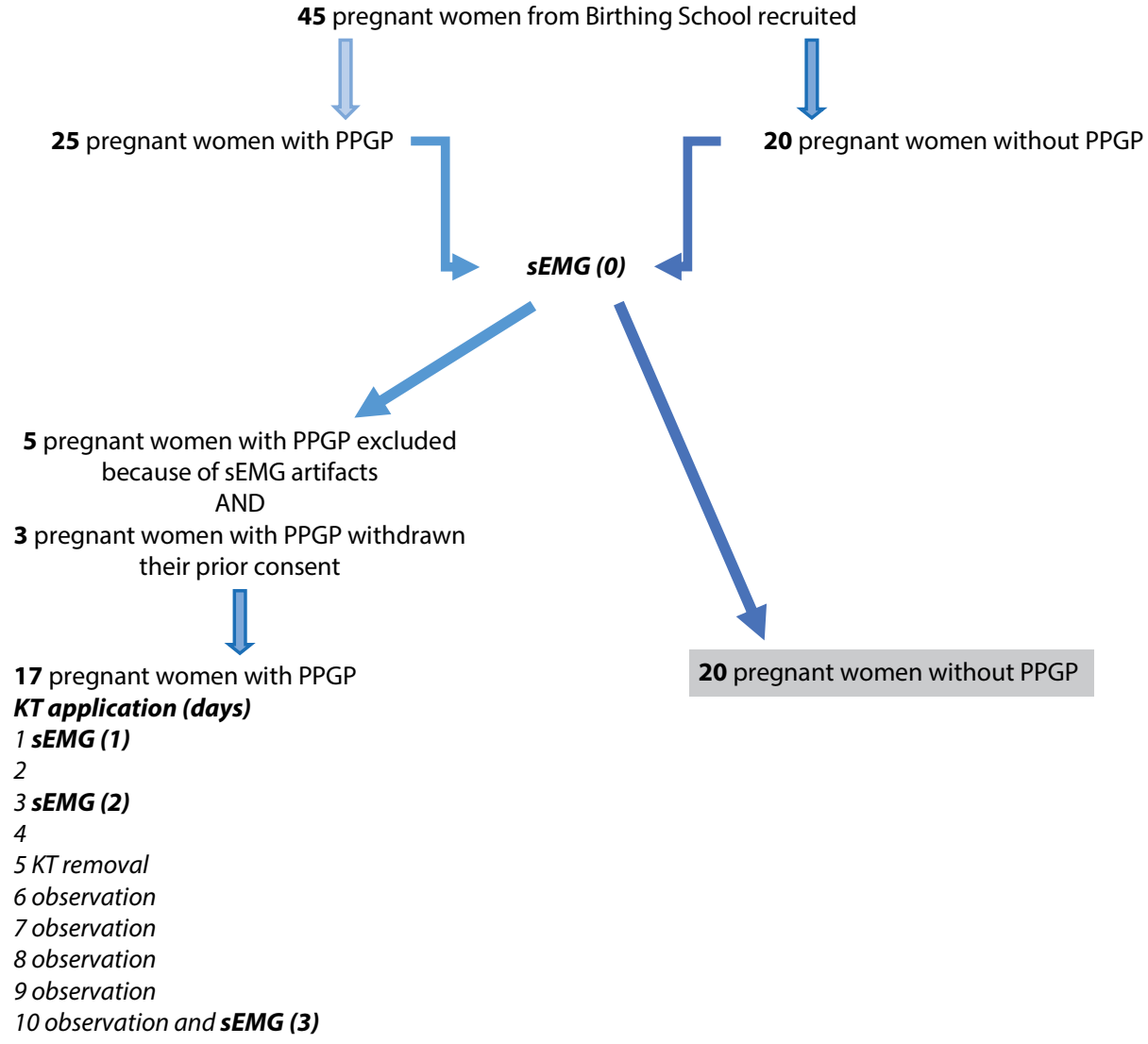

PPGP — Pregnancy-related Pelvic Girdle Pain; sEMG — surface electromyography; KT — Kinesio Taping, sEMG e KT application day 1, sEMG (1) - test immediately after KT application day 1, SEMG (2) test day 3 with KT application, sEMG (3) - test 5 days after KT removal

Figure 1. Recruitment of the patients and the course of intervention

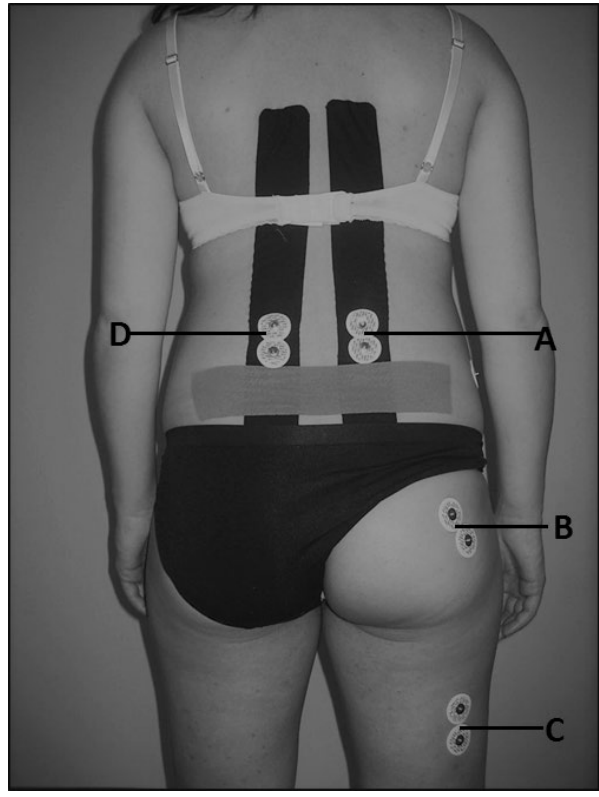

Figure 2. Application of the electrodes in compliance with the guidelines of the SENIAM A- ipsilateral erector spinae muscle, B-ipsilateral gluteus maximus muscle, C-ipsilateral biceps femoris muscle, D-contralateral erector spinae muscle control group. The patients filled out the same questionnaire as IG and gave consent to participate in the study Despite patients denying PPGP symptoms, the same examination and tests as for IG were performed. Only women with no symptomology of PPGP and negative tests were included in the CG.

\section{Intervention}

Kinesio Taping was used for five days in IG with I-shape application and then, in fifth day removed for the next five days follow-up. I-shape application is a KT technique, where elastic tape is applied with slight stretch (approximately 5\% of initial length) on the elongated target muscle (Fig. 2). The muscle application with $5 \%$ tape tension was applied to the extensor spinae muscles on either side of the spine during full flexion of the trunk position. The base of the tape was applied in the standing position, inferior to the line connecting the posterior superior iliac spine (PSIS) while its terminus was at the inferior angle of the scapula. The length of the tape was contingent on the height of the patient. In order to ensure the proper application of electrodes, both tapes had openings cut into them, $8 \mathrm{~cm}$ long and $2 \mathrm{~cm}$ wide starting 
at approximately the level of L1 vertebra. Application for the ligaments with approximately $50 \%$ tension was applied crosswise to the previous I-shape application at the level of the PSIS (Fig. 2).

\section{Surface Electromyography}

To assess the activity of the selected muscles stabilizing the SIJ, sEMG was used. The analysis was carried out on all participants. Subsequent measurements were only performed on women belonging to the IG (Fig. 1) and were performed as follows: directly after application of the KT, on the third day of tape use and on the tenth day of the study (five days after the tapes'removal to assess whether muscles' activity changes are still present despite tape removal). The muscles were assessed using 8 channels SEMG system TeleM9000 produced by the Noraxon company (USA), in cooperation with the MyoResearch MasterEdition programming and the four lead surface system Myotrace400 also from Noraxon, cooperating with MyoResearch MasterEdition programming. The muscles assessed through sEMG were : ipsi and contralateral erector spinae muscles of the lumbar spine (IES - ipsilateral erector spinae muscle, CES - contralateral erector spinae muscle), ipsilateral gluteus maximus (GM - gluteus maximus muscle) the ipsilateral biceps femoris muscle (BF - biceps femoris muscle). Single use pediatric gel electrodes from Bio Lead Lok B (produced by Vermed, Lendersdorf, Germany) with $\mathrm{Ag} / \mathrm{AgCl}$ senstrs with a diameter of $30 \mathrm{~mm}$ was used. The electrodes were applied in compliance with the guidelines of the SENIAM project (Fig. 2).

The analysis was carried out during a thrice repeated hip extension from a four-point kneeling position (due to advanced pregnancy) (Fig. 3 and 4) [12] in a room temperature 23 degrees Celsius. According to the protocol for extension of the lower limb the patient took a four-point kneeling position. After five seconds rest phase in this position and when given the command "Extend the hip" patient actively performed the test in the form of a three repetition

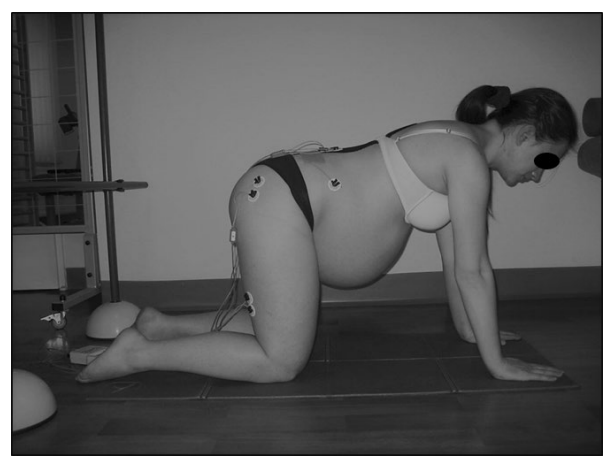

Figure 3. Rest phase in four-point kneeling position before performing the test of hip extension extension of the hip joint of the lower right limb, next followed by the same in the lower left limb. Each extension was separated by a five second resting phase.

\section{The sEMG data collection}

The three measurements were averaged and smoothed using the RMS (Root Mean Square - Square root of the mean in the specified time window) algorithm as well as cleaned from electrocardiogram (EKG) artifacts. The results of the amplitudes during movement were normalized with the help of the RVC (Reference Voluntary Contraction) method, relying on comparison of two different active assignments of the selected muscle (ratio of average values of amplitude of extension/rest phases) [13]. For the purpose of calculating results the "ONSET-OFFSET" formula was used as well as the "Average Activation" formula. The muscle was considered active during extension of the hip joint if the average resting tension from the first $100 \mathrm{~ms}$ of motion was three times higher than the sum of the average amplitude at rest and standard deviation during the first $100 \mathrm{~ms}$ [13].

\section{Variables of interest}

Epidemiological data was obtained for description purposes and to compare any possible differences between both groups. Information on internal disease in pregnancy was obtained to exclude other possible causes of pain other than PPGP.

VAS scores were obtained to asses intensity of pain in IG. Parameters registered on the SEMG examination in the study:

1. Resting amplitude in four-point kneeling position [uV].

2. Amplitude during extension of the hip joint from the four-point kneeling position registered from following ipsilateral muscles: extensor spinae (A), gluteus maximus (B), biceps femoris (C) as well as the contralateral extensor spinae muscle (D) [uV] (Fig. 2).

3. Muscle activation order time "Onset time" [s].

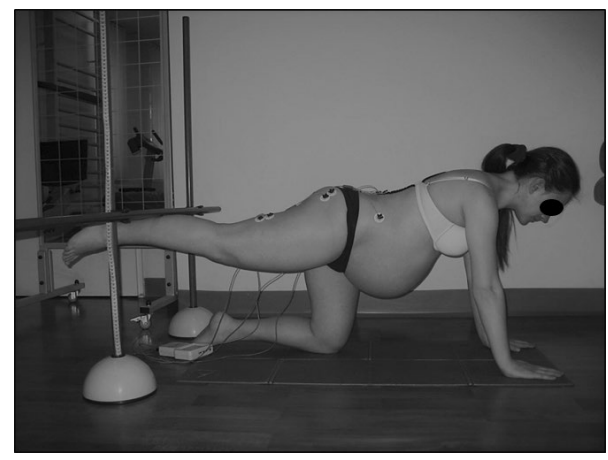

Figure 4. Hip extension in four-point kneeling position 


\section{Statistical analysis}

Ananalysis of the resultswas conducted with thehelp of the statistical packet PQSat ver. 1.4.2.324. Age (years), height (m), mass $(\mathrm{kg})$ and BMI $\left(\mathrm{kg} / \mathrm{m}^{2}\right)$ was compared with the Mann-Whitney U-test. The performed work in tested groups was compared using the dependency Pearson's Chi-square test with Yates correction. Results from IG and CG were analyzed with student t-test.VAS analysis was conducted through the Friedman ANOVA. Probability significance was set at $p<0.05$ and high probability significance was set at $p<0.01$.

\section{RESULTS}

\section{The characteristics of the examined groups}

In total, 17 women with confirmed PPGP and 20 healthy pregnant women were included in the study. Both groups were matched to the described characteristics (Tab. 1).

Table 2 shows the value of resting amplitude during sEMG examination in the four-point kneeling position. IG showed a higher resting activity of the GM compared to the CG before application of the tape $(p=0.003)$ as well as directly after application of the tape $(p=0.04)$, as well as on the tenth day of the study (five days after removing the tape) $(p=0.03)$. Additionally, on the tenth day of the study a significant increase in the resting of the CES muscle was noted in IG compared to the CG $(p=0.02)$.

Table 3 shows the order of muscle activation for select muscles during extension of lower limb in four-point kneeling position. In IG, the GM activates faster compared to the CG ( $p=0.007)$ when measured before application of the tape. Activation of the IES was significantly delayed when compared to the CG both, before application of the tape $(p=0.02)$, as well as after the application $(p=0.02)$.

\section{In the sEMG testing there was no statistical significance for:}

1. Differences in resting amplitude in IG between subsequent measurements of individual muscles.

2. Results of the mean amplitude of the extension/rest phases during the active hip extension in the four-point

\begin{tabular}{|c|c|c|c|c|c|}
\hline & \multirow{2}{*}{$\begin{array}{l}\text { Mean age } \\
\text { [years] } \\
\text { Mean SD }\end{array}$} & \multirow{2}{*}{$\begin{array}{l}\text { Mean } \\
\text { week of } \\
\text { pregnancy } \\
\text { Mean SD }\end{array}$} & \multirow{2}{*}{$\begin{array}{l}\text { BMI }^{\mathrm{a}} \\
{\left[\mathrm{kg} / \mathrm{m}^{2}\right]} \\
\text { Mean SD }\end{array}$} & \multicolumn{2}{|c|}{ Occupationa, n (\%) } \\
\hline & & & & Dynamic & Static \\
\hline $\begin{array}{l}\text { IG } \\
n=17\end{array}$ & $\begin{array}{l}30.5 \\
2.45\end{array}$ & $\begin{array}{l}29.6 \\
4.5\end{array}$ & $\begin{array}{l}27.9 \\
16.4\end{array}$ & $\begin{array}{l}4 \\
(23.5)\end{array}$ & $\begin{array}{l}13 \\
(76.47)\end{array}$ \\
\hline $\begin{array}{l}C G \\
n=20\end{array}$ & $\begin{array}{l}29.9 \\
4.6\end{array}$ & $\begin{array}{l}30.8 \\
2.5\end{array}$ & $\begin{array}{l}21.2 \\
2.5\end{array}$ & $\begin{array}{l}3 \\
(15)\end{array}$ & $\begin{array}{l}17 \\
(85)\end{array}$ \\
\hline$p$ & 0.31 & 0.71 & 0.11 & \multicolumn{2}{|l|}{0.81} \\
\hline
\end{tabular}

IG - intervention group, CG - control group, BMI — body mass index $\mathrm{a}-$ before pregnancy, $\mathrm{p} \leq 0.05$ statistical significance, Mann-Whitney U-test kneeling position between groups and between subsequent measurements in IG.

3. Differences between groups in relation to activation time of selected muscles as well as in the IG between subsequent measurements.

\section{Results from VAS assessment in IG on the days of EMG testing}

On the first day, before application of KT, the average score on VAS was 31 (SD = 23.2) $\mathrm{mm}$. On the third day of therapy the patients assessed their pain on average at 25.5 (SD = 23.6) $\mathrm{mm}$ and on the tenth day of the study (five days after removal of the plasters) they averaged $26.1(\mathrm{SD}=20.7) \mathrm{mm}$. Despite the decrease in self assessed pain values according to VAS, no statistical significance was found ( $p=0.31616$ ANOVA Friedman and Kendall's compatibility coefficient for $p \leq 0.05$ )

\section{DISCUSSION}

$\mathrm{KT}$ method is viewed to be effective in reducing pain level, improving function of the muscles and stability of the

\begin{tabular}{|c|c|c|c|c|}
\hline $\begin{array}{l}\text { Time of } \\
\text { measurement/ } \\
\text { /examined muscle }\end{array}$ & $\begin{array}{l}\text { IG }(n=17) \\
\text { Mean } \\
\text { amplitude } \\
\text { [uV] }\end{array}$ & $\begin{array}{l}\text { CG }(n=20) \\
\text { Mean } \\
\text { amplitude } \\
\text { [uV] }\end{array}$ & $\begin{array}{l}\text { Student } \\
\text { t-test }\end{array}$ & $\mathbf{p}$ \\
\hline $\begin{array}{l}\text { Before KT } \\
\text { application } \\
\text { IES } \\
\text { CES } \\
\text { GM } \\
\text { BF }\end{array}$ & $\begin{array}{l}5.04 \\
4.21 \\
5.22 \\
9.36\end{array}$ & $\begin{array}{l}4.88 \\
4.11 \\
2.75 \\
7.76\end{array}$ & $\begin{array}{l}0.17 \\
0.12 \\
3.16 \\
0.95\end{array}$ & $\begin{array}{l}0.86 \\
0.90 \\
\mathbf{0 . 0 0 3} \\
0.34\end{array}$ \\
\hline $\begin{array}{l}\text { Immediately after } \\
\text { KT application in IG } \\
\text { IES } \\
\text { CES } \\
\text { GM } \\
\text { BF }\end{array}$ & $\begin{array}{l}4.27 \\
5.34 \\
6.71 \\
7.25\end{array}$ & $\begin{array}{l}4.88 \\
4.11 \\
2.75 \\
7.76\end{array}$ & $\begin{array}{l}-0.91 \\
1.56 \\
2.03 \\
-0.35\end{array}$ & $\begin{array}{l}0.36 \\
0.12 \\
0.04 \\
0.72\end{array}$ \\
\hline $\begin{array}{l}\text { Three days of KT } \\
\text { application in IG } \\
\text { IES } \\
\text { CES } \\
\text { GM } \\
\text { BF }\end{array}$ & $\begin{array}{l}5.85 \\
4.92 \\
6.17 \\
8.57\end{array}$ & $\begin{array}{l}4.88 \\
4.11 \\
2.75 \\
7.76\end{array}$ & $\begin{array}{l}1.22 \\
0.74 \\
1.80 \\
0.52\end{array}$ & $\begin{array}{l}0.23 \\
0.45 \\
0.08 \\
0.60\end{array}$ \\
\hline $\begin{array}{l}\text { Five days after } K T \\
\text { remove } \\
\text { IES } \\
\text { CES } \\
\text { GM } \\
\text { BF }\end{array}$ & $\begin{array}{l}6.12 \\
6.04 \\
4.15 \\
10.17\end{array}$ & $\begin{array}{l}4.88 \\
4.11 \\
2.75 \\
7.76\end{array}$ & $\begin{array}{l}1.21 \\
2.27 \\
2.21 \\
1.40\end{array}$ & $\begin{array}{l}0.23 \\
0.02 \\
0.03 \\
0.16\end{array}$ \\
\hline
\end{tabular}

G - interventionl group; CG — control group; KT — Kinesio Taping; sEMG - surface electromyography; IES - ipsilateral erector spinae muscle; CES - contralateral erector spinae muscle; GM — gluteus maximus muscle; $\mathrm{BF}$ - biceps femoris muscle; $\mathrm{p} \leq 0.05$ statistical significance; student $\mathrm{t}$-test 
Table 3. Differences in order of muscles activation for selected muscles during extension of lower limb at the hip joint in four-point kneeling position between intervention (IG) and control group (CG)

\begin{tabular}{|c|c|c|c|c|}
\hline $\begin{array}{l}\text { Time of measurement/ } \\
\text { /examined muscle }\end{array}$ & $\begin{array}{l}\text { IG } \\
(n=17) \\
\text { Mean } \\
\text { time }[s]\end{array}$ & $\begin{array}{l}\text { CG } \\
(n=20) \\
\text { Mean } \\
\text { time }[s]\end{array}$ & $\begin{array}{l}\text { Student } \\
\text { t-test }\end{array}$ & $\mathbf{p}$ \\
\hline $\begin{array}{l}\text { Before KT application } \\
\text { IES } \\
\text { CES } \\
\text { GM } \\
\text { BF }\end{array}$ & $\begin{array}{l}0.83 \\
0.64 \\
0.65 \\
0.87\end{array}$ & $\begin{array}{l}0.47 \\
0.62 \\
0.98 \\
0.98\end{array}$ & $\begin{array}{l}2.49 \\
0.15 \\
-2.81 \\
-0.74\end{array}$ & $\begin{array}{l}\mathbf{0 . 0 1} \\
0.87 \\
\mathbf{0 . 0 0 7} \\
0.45\end{array}$ \\
\hline $\begin{array}{l}\text { Immediately after KT } \\
\text { application in IG } \\
\text { IES } \\
\text { CES } \\
\text { GM } \\
\text { BF }\end{array}$ & $\begin{array}{l}0.82 \\
1.08 \\
0.90 \\
0.75\end{array}$ & $\begin{array}{l}0.47 \\
0.62 \\
0.98 \\
0.98\end{array}$ & $\begin{array}{l}2.40 \\
1.93 \\
-0.59 \\
-1.60\end{array}$ & $\begin{array}{l}\mathbf{0 . 0 2} \\
0.06 \\
0.55 \\
0.11\end{array}$ \\
\hline $\begin{array}{l}\text { Three days of KT } \\
\text { application in IG } \\
\text { IES } \\
\text { CES } \\
\text { GM } \\
\text { BF }\end{array}$ & $\begin{array}{l}0.75 \\
0.61 \\
0.85 \\
0.86\end{array}$ & $\begin{array}{l}0.47 \\
0.62 \\
0.98 \\
0.98\end{array}$ & $\begin{array}{l}1.66 \\
-0.09 \\
-1.23 \\
-0.88\end{array}$ & $\begin{array}{l}0.10 \\
0.92 \\
0.22 \\
0.37\end{array}$ \\
\hline $\begin{array}{l}\text { Five days after } K T \text { remove } \\
\text { IES } \\
\text { CES } \\
\text { GM } \\
\text { BF }\end{array}$ & $\begin{array}{l}0.54 \\
0.64 \\
0.75 \\
0.81\end{array}$ & $\begin{array}{l}0.47 \\
0.62 \\
0.98 \\
0.98\end{array}$ & $\begin{array}{l}0.52 \\
0.14 \\
-1.95 \\
-1.32\end{array}$ & $\begin{array}{l}0.60 \\
0.88 \\
0.05 \\
0.19\end{array}$ \\
\hline
\end{tabular}

IG - intervention group, CG — control group, KT — Kinesio Taping, sEMG - surface electromyography, IES - ipsilateral erector spinae muscle, CES - contralateral erector spinae muscle GM - gluteus maximus muscle, $\mathrm{BF}$ - biceps femoris muscle, $\mathrm{p} \geq 0.05$ - statistical significance, student $t$-test

joints. Decision on the type of application is based on the specific goal: pain relief, joint stabilization, facilitating of the weakened muscles or relaxation of the overloaded ones [14]. Elastic tape used in KT contains folds on the tape's surface, what may support mechanically muscles and ligaments by lifting the skin. The space between skin and tissues below improves blood supply in area of soft tissues and facilitates lymphatic fluid movement. In addition, KT provides stimulation of the cutaneous receptors and proprioceptive feedback $[11,14]$.

To our best knowledge this is the first study which measures activation of the muscles stabilizing SIJ in pregnant women with and without PPGP.

According to the results the most important findings are that women suffering from PPGP have higher resting activity of GM, the muscle activates faster compared to the healthy subjects and that KT application appears to delay activation of GM in group with PPGP.

The statistical significance was obtained in each of the sEMG time-points only for the GM muscle. The reasons may be twofold. First, because women in advanced pregnancy with increasing abdominal circumference adopt a position which moves the center of gravity posterior. Following this the spine and particularly the lumbar curve undergoes a flattening, and the sacral bone undergoes posterior pelvic tilt which leads to diminished stability of the SIJ [15]. Moreover, in advanced pregnancy the joint capsule of the SIJ is relaxed (diminished form closure) and the ligaments of the pelvis also are relaxed (diminished force closure) [16]. In this condition pelvic positioning the GM has increased activity to compensate diminished tension of SIJ ligaments which leads to pain appearance in loading $[17,18]$. Moreover, the thoracolumbar fascia (TLF) has a huge influence on SIJ stability through connection of the deep fibers to the GM fibers. The exertion of the TLF changes in the PPGP as a result of the changes in GM tension [19]. In our study, the resting activity of GM in IG increased when KT was applied. IES was released only immediate after KT application and in the next sessions of sEMG tests started to increase with the highest value in the $10^{\text {th }}$ day of the test. The KT application used in our study might act on the studied muscles in two ways: elevating the skin, which enlarged the space between skin and TLF and improves the blood circulation and through this facilitates muscle contraction. Moreover, by acting on the skin receptors we speculate that KT inhibits the pain and improves body posture by acting on proprioceptors [20-22].

During the extension of the hip joint in the CG, the IES and CES were activated before the GM. In contrast to this for the IG we observed delayed activation of the extensor muscles (especially for IES) with previous activation of the GM. This activation time was reversed to the normal pattern at the $3^{\text {rd }}$ day of KT application (it assumes values similar to the control group $p=0.1$ for IES and $p=0.2$ for GM) and was maintained until five days after the tapes removal $(p=0.6$ for IES and $p=0.058$ for GM). Differences in activation time for the GM were observed just after tapes application $(p=0.55)$ and were maintained five days after removing the tapes with slow regression observed $(p=0.058)$. The quicker activation of the GM may be tied to increased resting tension [17]. We speculate that facilitation of IES activity after KT application might delay activation of GM during hip extension in the next sEMG sessions.

PPGP is one of the most frequently reported complaints during pregnancy, affecting normal daily activities for many pregnant women. The risk of development of PPGP is increasing with numbers of previous parities, in women with higher maternal age and pre-pregnancy overweight and obesity. Higher BMI is a risk factor for musculoskeletal disorders, osteoarthritis, low back and pelvic girdle pain, and gait problems. In PPGP, where transfer of the loads between trunk through pelvis to the lower limbs during walking, is disabled, increased BMI and weight gain may increase disability and pain connected with overloading of the SIJ area $[23,24]$. In this study, we have been able to demonstrate 
a different activity pattern in pregnant women with compared to women without PPGP, suggesting that this altered activity pattern may play a role in PPGP. The application of KT may be a possible favourable and non-pharmaceutical treatment approach for women with PPGP in advanced pregnancy $[25,26]$. The sEMG testing in addition to VAS assessment may provide complex information regarding the correlation between perception of pain and changes in activity of muscles stabilizing the lumbar-pelvic area. Up until now, KT has been assessed, primarily as supplemental therapy which provided an unclear picture on the influence of KT on pelvic pain [27], furthermore, questionnaires and VAS scales were used to assess the influence of KT on pain level and quality of life, which records only the subjective perceptions of the patient while skipping assessment of objective parameters such as measurements recorded by SEMG [28]. In pregnant women, where the muscle activity is greater due to ligament weakness, continuation of the above testing is indicated. Assessment of activity of selected muscles through physical training jointly with KT as analgesic therapy would seem to be a promising field to investigate as well.

\section{Limitations of the study}

One of the study limits is the small number of participants. Bigger sample size could control the risk of false-negative findings interpretation [29]. sEMG is wildly used to record static and dynamic activity of the muscles. It is a valuable, qualitative tool to assess the effects of any intervention in rehabilitation including KT application [30]. To characterize the activity of selected muscles, it is important to choose proper parameters of sEMG. The use of normalization method is important to interpret the results of amplitude parameters and the most common is maximal voluntary contraction (MVC) normalization [31, 32]. In our study, to assess the amplitude during extension of the hip joint in the four-point kneeling position, the RVC method was used, because of characteristics of the participants (advanced pregnancy). For this reasoning our data cannot be compared to other studies, where another normalization method was used. The four-point kneeling position in pregnant women was used for the first time to assess activity of muscles working in co-contraction in the area of the lumbar-pelvic complex. The sEMG in pregnant women was previously used to assess pain in the lumbar region, however only from a standing position [33]. The four-point kneeling position used in our study makes comparison of our observations to widely reported studies using the Prone Hip Extension (PHE) position impossible [34]. Also, it seems to be useful to apply tapes for a longer time and to perform sEMG testing at several additional "time points", eg. immediately after tapes removal, in future studies.

\section{CONCLUSIONS}

Women suffering from PPGP have increased resting activity of GM. The application of KT in the lumbar region appears to alter the activation of the GM muscle as well as improve activation of IES muscle during hip extension from four-point-kneeling-position. By acting on electrical parameters of muscles in selected area, Kinesio Taping method could be a helpful tool to relieve pain in such group of patients. More research about correlation between changes in tested muscles activity pattern and intensity of pain in SIJ area need to be further considered.

\section{Acknowledgements}

We wish to acknowledge the contributions of prof. dr hab. $n$. med. Andrzej Karmowski and prof. dr hab. n. med. Mariusz Zimmer in the recruitment of the subjects.

\section{REFERENCES}

1. Vleeming A, Albert HB, Ostgaard HC, et al. European guidelines for the diagnosis and treatment of pelvic girdle pain. Eur Spine J. 2008; 17(6): 794-819, doi: 10.1007/s00586-008-0602-4, indexed in Pubmed: 18259783.

2. Wu WH, Meijer OG, Uegaki K, et al. Pregnancy-related pelvic girdle pain (PPP), I: Terminology, clinical presentation, and prevalence. Eur Spine J. 2004; 13(7): 575-589, doi: 10.1007/s00586-003-0615-y, indexed in Pubmed: 15338362 .

3. Nilsson-Wikmar L, Holm K, Oijerstedt R, et al. Effect of three different physical therapy treatments on pain and activity in pregnant women with pelvic girdle pain: a randomized clinical trial with 3,6 , and 12 months follow-up postpartum. Spine (Phila Pa 1976). 2005; 30(8): 850-856, doi: 10.1097/01.brs.0000158870.68159.d9, indexed in Pubmed: 15834325.

4. Kanakaris NK, Roberts CS, Giannoudis PV. Pregnancy-related pelvic girdle pain: an update. BMC Med. 2011; 9: 15, doi: 10.1186/1741-7015-9-15, indexed in Pubmed: 21324134.

5. Pierce $H$, Homer CSE, Dahlen HG, et al. Pregnancy-related lumbopelvic pain: listening to Australian women. Nurs Res Pract. 2012; 2012: 387428 , doi: 10.1155/2012/387428, indexed in Pubmed: 22685643.

6. Bastiaanssen JM, de Bie RA, Bastiaenen CHG, et al. Etiology and prognosis of pregnancy-related pelvic girdle pain; design of a longitudinal study. BMC Public Health. 2005; 5: 1, doi: 10.1186/1471-2458-5-1, indexed in Pubmed: 15627405.

7. Kuciel N, Sutkowska E, Cienska A, et al. Impact of Kinesio Taping application on pregnant women suffering from pregnancy-related pelvic girdle pain - preliminary study. Ginekol Pol. 2017; 88(11): 620-625, doi: 10.5603/GP.a2017.0111, indexed in Pubmed: 29303216.

8. Gutke A, Betten C, Degerskär K, et al. Treatments for pregnancy-related lumbopelvic pain: a systematic review of physiotherapy modalities. Acta Obstet Gynecol Scand. 2015; 94(11): 1156-1167, doi: 10.1111/aogs.12681, indexed in Pubmed: 26018758.

9. Liddle S, Pennick V. Interventions for preventing and treating low-back and pelvic pain during pregnancy. Cochrane Database of Systematic Reviews. 2015, doi: 10.1002/14651858.cd001139.pub4.

10. KiebzakW, Kowalski I, Pawłowski M, et al. The use of Kinesiology Taping in physiotherapy practice: a systematic review of the literature. Polish Journal of Physiotherapy. 2012; 12(1): 1-11, doi: 10.5604/16420136.990847.

11. Morris $D$, Jones $D$, Ryan $H$, et al. The clinical effects of Kinesio ${ }^{\oplus}$ Tex taping: A systematic review. Physiother Theory Pract. 2013; 29(4): 259-270, doi: 10.3109/09593985.2012.731675, indexed in Pubmed: 23088702.

12. Soderberg GL, Knutson LM. A guide for use and interpretation of kinesiologic electromyographic data. Phys Ther. 2000; 80(5): 485-498, indexed in Pubmed: 10792859.

13. Ghofrani M, Olyaei G, Talebian S, et al. Reliability of SEMG measurements for trunk muscles during lifting variable loads in healthy subjects. J Bodyw Mov Ther. 2017; 21(3): 711-718, doi: 10.1016/j.jbmt.2016.12.003, indexed in Pubmed: 28750989.

14. Yasukawa $A$, Patel $P$, Sisung C. Pilot study: investigating the effects of Kinesio Taping in an acute pediatric rehabilitation setting. Am J Oc- 
cup Ther. 2006; 60(1): 104-110, doi: 10.5014/ajot.60.1.104, indexed in Pubmed: 16541989.

15. Albert $\mathrm{H}$, Godskesen $\mathrm{M}$, Westergaard J. Evaluation of clinical tests used in classification procedures in pregnancy-related pelvic joint pain. Eur Spine J. 2000; 9(2): 161-166, doi: 10.1007/s005860050228, indexed in Pubmed: 10823434.

16. Gutke A, Hansson ER, Zetherström G, et al. Posterior pelvic pain provocation test is negative in patients with lumbar herniated discs. Eur Spine J. 2009; 18(7): 1008-1012, doi: 10.1007/s00586-009-1003-z, indexed in Pubmed: 19390876.

17. Koumantakis GA, Oldham JA, Winstanley J. Intermittent isometric fatigue study of the lumbar multifidus muscle in four-point kneeling: an intra-rater reliability investigation. Man Ther. 2001; 6(2): 97-105, doi: 10.1054/math.2001.0392, indexed in Pubmed: 11414779.

18. Kielnar R, Oleksy $Ł$, Grzegorczyk J. Różnicowanie napięć bioelektrycznych mięśni przykręgosłupowych u aktywnych seniorów przy użyciu powierzchniowego EMG. Rehabil Med. 2012; 16(3): 9-15.

19. Sipko T, Grygier D, Barczyk K, et al. The occurrence of strain symptoms in the lumbosacral region and pelvis during pregnancy and after childbirth. J Manipulative Physiol Ther. 2010; 33(5): 370-377, doi: 10.1016/j. jmpt.2010.05.006, indexed in Pubmed: 20605556.

20. van Wingerden JP, Vleeming A, Buyruk HM, et al. Stabilization of the sacroiliac joint in vivo: verification of muscular contribution to force closure of the pelvis. Eur Spine J. 2004; 13(3): 199-205, doi: 10.1007/s00586-0030575-2, indexed in Pubmed: 14986072.

21. van Wingerden JP, Vleeming $A$, Ronchetti I. Differences in standing and forward bending in women with chronic low back or pelvic girdle pain: indications for physical compensation strategies. Spine (Phila Pa 1976). 2008; 33(11): E334-E341, doi: 10.1097/BRS.0b013e318170fcf6, indexed in Pubmed: 18469680.

22. Pool-Goudzwaard AL, Vleeming A, Stoeckart R, et al. Insufficient lumbopelvic stability: a clinical, anatomical and biomechanical approach to 'a-specific' low back pain. Man Ther. 1998; 3(1): 12-20, doi: 10.1054/math.1998.0311, indexed in Pubmed: 11487296.

23. Biering K, Nøhr EA, Olsen J, et al. Pregnancy-related pelvic pain is more frequent in women with increased body mass index. Acta Obstet Gynecol Scand. 2011; 90(10): 1132-1139, doi: 10.1111/j.1600-0412.2011. 01141.x, indexed in Pubmed: 21446932

24. Mogren IM. BMI, pain and hyper-mobility are determinants of long-term outcome for women with low back pain and pelvic pain during preg- nancy. Eur Spine J. 2006; 15(7): 1093-1102, doi: 10.1007/s00586-0050004-9, indexed in Pubmed: 16404613.

25. Barker PJ, Hapuarachchi KS, Ross JA, et al. Anatomy and biomechanics of gluteus maximus and the thoracolumbar fascia at the sacroiliac joint. Clin Anat. 2014; 27(2): 234-240, doi: 10.1002/ca.22233, indexed in Pubmed: 23959791.

26. Wu WT, Hong CZ, Chou LW. The Kinesio Taping Method for Myofascial Pain Control. Evid Based Complement Alternat Med. 2015; 2015: 950519 , doi: 10.1155/2015/950519, indexed in Pubmed: 26185522.

27. Sihvonen T, Huttunen $M$, Makkonen $M$, et al. Functional changes in back muscle activity correlate with pain intensity and prediction of low back pain during pregnancy. Arch Phys Med Rehabil. 1998; 79(10): 1210-1212, doi: 10.1016/s0003-9993(98)90264-7, indexed in Pubmed: 9779673.

28. Bruno P, Bagust J, Cook J, et al. An investigation into the activation patterns of back and hip muscles during prone hip extension in non-low back pain subjects: Normal vs. abnormal lumbar spine motion patterns. Clinical Chiropractic. 2008; 11(1): 4-14, doi: 10.1016/j. clch.2008.01.001.

29. Biau DJ, Kernéis S, Porcher R. Statistics in brief: the importance of sample size in the planning and interpretation of medical research. Clin Orthop Relat Res. 2008; 466(9): 2282-2288, doi: 10.1007/s11999-008-0346-9, indexed in Pubmed: 18566874.

30. Neblett $R$, Brede E, Mayer TG, et al. What is the best surface EMG measure of lumbar flexion-relaxation for distinguishing chronic low back pain patients from pain-free controls? Clin J Pain. 2013; 29(4): 334-340, doi: 10.1097/AJP.0b013e318267252d, indexed in Pubmed: 23328325.

31. De Blaiser C, De Ridder R, Willems $T$, et al. Evaluating abdominal core muscle fatigue: Assessment of the validity and reliability of the prone bridging test. Scand J Med Sci Sports. 2018; 28(2): 391-399, doi: 10.1111/sms.12919, indexed in Pubmed: 28544083.

32. Vera-Garcia FJ, Moreside JM, McGill SM. MVC techniques to normalize trunk muscle EMG in healthy women. J Electromyogr Kinesiol. 2010; 20(1): 10-16, doi: 10.1016/j.jelekin.2009.03.010, indexed in Pubmed: 19394867.

33. Lehman GJ, Lennon D, Tresidder B, et al. Muscle recruitment patterns during the prone leg extension. BMC Musculoskelet Disord. 2004; 5: 3, doi: 10.1186/1471-2474-5-3, indexed in Pubmed: 15028110.

34. Hungerford B, Gilleard W, Hodges P. Evidence of altered lumbopelvic muscle recruitment in the presence of sacroiliac joint pain. Spine (Phila Pa 1976). 2003; 28(14): 1593-1600, indexed in Pubmed: 12865851. 